\title{
Effect of a Homogeneous Combustion Catalyst on the Nanostructure and Oxidative Properties of Soot from Biodiesel Combustion in a Compression Ignition Engine
}

\author{
Yu Ma, Mingming Zhu, Zhezi Zhang and Dongke Zhang* \\ Centre for Energy (M473), The University of Western Australia, 35 Stirling Highway, \\ Crawley, WA 6009, Australia
}

\begin{abstract}
*Corresponding author:
Professor Dongke Zhang

Email: dongke.zhang@uwa.edu.au

Phone: +61 864887600

Fax: $\quad+61864887235$
\end{abstract}

(A manuscript offered to the $35^{\text {th }}$ International Symposium on Combustion)

Name of Colloquium: Soot, PAH and Other Large Molecules

Total Length of Paper: 5828 words (Method 1)

\begin{tabular}{|c|c|c|}
\hline Title & word equivalent details & word equivalent \\
\hline Main text & Computer Count & 3119 \\
\hline Table 1 & (8 text lines +2 lines) $\mathrm{x}$ (7.6 words/line) $\mathrm{x}$ (1 columns) & 76 \\
\hline Table 2 & (5 text lines+ 2 lines) x (7.6 words/line) x (1 columns) & 53 \\
\hline Table 3 & (6 text lines +2 lines) $\mathrm{x}(7.6$ words/line $) \times(2$ columns $)$ & 122 \\
\hline Table 4 & (5 text lines +2 lines) $\mathrm{x}$ (7.6 words/line) $\mathrm{x}$ (1 columns) & 53 \\
\hline Table 5 & (5 text lines+ 2 lines) $\mathrm{x}$ (7.6 words/line) $\mathrm{x}$ (1 columns) & 53 \\
\hline Figure 1 & {$[(98 \mathrm{~mm}+10 \mathrm{~mm}) \times(2.2$ words $/ \mathrm{mm}) \times(2$ columns $)]+27$ words in caption } & 502 \\
\hline Figure 2 & {$[(121 \mathrm{~mm}+10 \mathrm{~mm}) \times(2.2$ words $/ \mathrm{mm}) \times(1$ columns $)]+26$ words in caption } & 315 \\
\hline Figure 3 & {$[(109 \mathrm{~mm}+10 \mathrm{~mm}) \times(2.2$ words $/ \mathrm{mm}) \times(2$ columns $)]+20$ words in caption } & 544 \\
\hline Figure 4 & {$[(92 \mathrm{~mm}+10 \mathrm{~mm}) \times(2.2$ words $/ \mathrm{mm}) \times(1$ columns $)]+27$ words in caption } & 252 \\
\hline Figure 5 & {$[(51 \mathrm{~mm}+10 \mathrm{~mm}) \times(2.2$ words $/ \mathrm{mm}) \times(1$ columns $)]+11$ words in caption } & 145 \\
\hline References & (32 references +2$) \times(2.3$ lines/reference) $\mathrm{x}$ (7.6 words/line) & 594 \\
\hline Total & & 5828 \\
\hline
\end{tabular}




\section{Abstract}

The effect of a ferrous picrate based homogeneous combustion catalyst on the properties of soot from the combustion of a biodiesel in a compression ignition engine was systematically studied. Soot samples from the combustion of a reference petroleum diesel (RD) and the biodiesel (BD), with and without the catalyst treatment, were collected when the engine was maintained under a constant condition of 2800rpm speed and 5.5Nm load, and subsequently analysed using transmission electron microscopy (TEM) for their nanostructures and thermogravimetric analyser (TGA) for the oxidative reactivity. The results showed that compared to the soot from BD, the sizes of both primary soot and aggregates from the catalyst treated biodiesel were consistently smaller; while the nanostructure and fractal dimension remained similar, indicating that there were no dramatic changes in the mechanisms of the soot nucleation and agglomeration. Furthermore, soot from the catalyst treated biodiesel possessed higher oxidative reactivity as indicated by the lower ignition temperature and faster oxidation rate than those of soot from BD. In addition, the primary soot and aggregates from $\mathrm{BD}$ were smaller and the soot had a higher order in its nanostructure with greater oxidative reactivity, in comparison to those from RD. A mechanism of the working of the catalyst was proposed in that the catalyst promotes the biodiesel combustion process leaving fewer soot precursors and also accelerates the oxidation of soot particles, resulting in smaller sizes of the primary soot and soot aggregates and the reduced overall soot emissions.

Keywords: Biodiesel; Compression ignition engine; Homogeneous combustion catalyst; Iron; Soot oxidation 


\section{Introduction}

Compression ignition (CI) engines, commonly known as diesel engines, have found widespread applications in transportation, mobile heavy equipment, mining and power generation in remote areas [1]. However, the ever-increasing demand for diesel engines has led to its dominance as a major source of pollutants threatening urban air quality, human health and the environment. Soot emissions from diesel engines have been under increasing scrutiny for their high carcinogenic risks to human health and adverse impacts on ambient air quality $[1,2]$. Recently, with the enforcement of more stringent emission regulations as well as the need to improve the fuel economy, the search for alternative and clean fuels has been strongly motivated [3-6].

As an oxygenated, sulphur-free and biodegradable fuel, biodiesel has been extensively studied for its direct application in CI engines. Biodiesel is a mixture of mono-alkyl esters of fatty acids derived from a wide range of vegetable oils and animal fats and can be used either alone or in blends with conventional diesel [5-7]. In general, biodiesel features a higher viscosity, density, flash point, Cetane number and a lower calorific value than those of diesel [6-9]. These specific fuel properties can directly affect the combustion performance and emission characteristics of biodiesel in CI engines. It has been reported in the literature [7-9] including the authors' work [10] that, compared to petroleum diesel, the combustion of biodiesel generates less carbon monoxide (CO), unburned hydrocarbons (UHC) and soot, at the expense of slightly higher fuel consumption.

Further improvements in engine performance of biodiesel can be achieved by the application of metal-based homogeneous combustion catalysts (HCCs), also known as fuel borne catalysts in the literature [11-14]. These catalysts contain a metallic part to promote the fuel 
combustion and an organic part to make the molecule soluble in hydrocarbon fuels. A novel combustion catalyst, called fuel performance catalyst or FPC, has been extensively studied in the authors' previous work [10, 15-19]. FPC is composed of ferrous picrate as the active ingredient in a solvent solution of short-chain alkyl benzenes to form a continuous phase with diesel fuel. It has been confirmed that the FPC is capable of reducing up to $39.5 \%$ smoke, 22.5\% CO and 15.3\% UHC emissions and saving up to $4.2 \%$ fuel consumption from diesel combustion in CI engines [15, 16]. Extending the application to biodiesel combustion, it was found that the FPC can effectively reduce up to $24.4 \%$ smoke, $17.3 \%$ CO and $3.8 \%$ UHC emissions and save up to $2.8 \%$ biodiesel consumption [10].

Soot particles, the main substance responsible for the smoke in the engine exhausts, typically occur in the fuel-rich regions during combustion and deserve a further investigation. They possess very complex physical and chemical properties, which are closely correlated to the fuel formulation and combustion conditions [20, 21]. Literature reports have shown that soot from the oxygenated fuels carries surface oxygen functional groups and displays a higher degree of graphitisation, faster oxidation rate and smaller particle size [8, 9, 22]. It has also been reported that the metal-based HCCs have the potential to affect soot formation during the combustion processes, causing observable changes in soot particle size, microstructure and oxidative reactivity [23]. In the authors' previous study [17], the mechanisms of FPC in soot formation processes were ascertained by characterising the soot particles from the combustion of untreated and catalyst treated diesel fuels. Therefore, it is of vital importance to examine the effect of FPC in altering the key properties of soot from biodiesel combustion in CI engines, which can provide valuable insights into the catalytic mechanisms in biodiesel soot formation and oxidation processes. 
As a part of our continuing campaign to better understand soot emissions and control from CI engines, the present contribution reports a comprehensive study into the effect of FPC on the nanostructure and oxidative properties of biodiesel soot, as compared to that of petroleum diesel, from a laboratory diesel engine. A thermophretic sampling technique and filter paper were used to collect soot particles from the combustion of various fuels, including reference diesel and biodiesel, with and without FPC addition. These soot samples were analysed using transmission electron microscopy (TEM) and thermogravimetric analyser (TGA). The detailed nanostructure and oxidative properties thus revealed would allow a thorough understanding of the influence of FPC in soot formation processes during the biodiesel combustion.

\section{Experimental}

Four fuels were employed in this work, designed to contrast the differences in soot characteristics between petroleum diesel and biodiesel and to study the effect of a ferrous picrate-based combustion catalyst (FPC). A commercial petroleum diesel from a local service station (Caltex Australia Ltd) was used as the reference diesel (denoted as "RD”). A biodiesel (denoted as "BD”) derived from the transesterification of soybean oil, rapeseed oil and animal tallow with methanol was provided by BioWorks Australia Pty Ltd. The key properties of RD and BD were determined and are presented in Table 1. It is clearly seen that compared to RD, the biodiesel had a higher viscosity and density, which is expected to affect the fuel injection and atomisation and thus combustion in the engine [9]. A higher flash point was observed with $\mathrm{BD}$, indicating the lower fuel volatility. The distillation range of $\mathrm{BD}$ was much narrower than that of $\mathrm{RD}$, which is expected since $\mathrm{BD}$ is made of a narrower range of molecules than petroleum diesel [7]. The Cetane index of $\mathrm{BD}$ was higher than that of $\mathrm{RD}$, being 57.1 versus 
50.1, suggesting that the biodiesel combustion in a CI engine would incur a shorter ignition delay than diesel.

The FPC catalyst, provided by Fuel Technology Pty Ltd, was added into the RD and BD fuels at the ratio of 1:10000 ( $\mathrm{vol} / \mathrm{vol})$. For convenience, the catalyst-treated diesel and biodiesel fuels were abbreviated as "FPC-D (1:10000)" and "FPC-B (1:10000)", respectively. Analysis confirmed that the FPC addition at this dosing ratio did not noticeably alter the properties from those of RD and RB.

Details of the engine and soot collection system have been described elsewhere [16, 18]. Briefly, a four-stroke, single cylinder, direct injection CI engine (YANMAR L48AE, AET Ltd) was employed to generate the soot particles. The engine had a 70 $\mathrm{mm}$ bore, $55 \mathrm{~mm}$ stroke, $211 \mathrm{~cm}^{3}$ displacement and compression ratio of 19.9:1. A Zöllner TypeA-100, water cooled, electric dynamometer was coupled to the engine output shaft to provide the load conditions. During soot collection, the engine was maintained under 2800rpm speed and 5.5Nm load (equivalent to $75 \%$ of the maximum load). Note that it was desirable to operate the engine under a constant condition to enable consistent sampling of the soot for detailed characterisation, also consistent with our previous work $[17,18]$. This was justified as the engine operating conditions would not significantly alter the catalytic mechanisms of FPC during soot formation. When the engine was stabilised, a glass fibre filter paper (Whatman GF/A, $1.6 \mu \mathrm{m}$ pore size) supported on a ceramic holder was inserted perpendicular to the exhaust path to collect bulk soot for 3h. The soot was then scratched off the filter paper and stored in a desiccator before analysis. For TEM analysis, the soot particles were directly sampled from the exhaust using a thermophoretic sampling technique, as described elsewhere $[17,18]$. The technique involved a 30mm-long grid holder with TEM copper grids (200 mesh, 
holey carbon film coating), which was inserted parallel to the exhaust flow by a step motor for a rapid soot collection. Three samples were taken consecutively from each fuel run to ensure the repeatability of the subsequent sample analysis.

The structural properties of the soot samples at nanoscale were examined using a JEOL 2100 TEM operating at the accelerating voltage of $120 \mathrm{kV}$ and magnifications from $5000 \times$ to 50,000×. The TEM images were processed using the DigitalMicrograph software (Gatan Inc). These 2-D images of soot were found to be sufficient to reveal the 3-D features, including sizes and size distributions of the primary soot and soot aggregates, as well as their fractal properties.

The bulk soot samples were subject to analysis in a thermogravimetric analyser (Model SDTQ600, TA instrument) operating in non-isothermal mode for determining their oxidative properties. The TGA tests were conducted in air (instrument grade) at a flow rate of $15 \mathrm{ml}$ $\min ^{-1}[18] .5 .5 \sim 6.0 \mathrm{mg}$ of a soot sample was loaded in the alumina crucible and heated from $25^{\circ} \mathrm{C}$ to $700^{\circ} \mathrm{C}$ at a heating rate of $10^{\circ} \mathrm{C} \mathrm{min}^{-1}$. The heating rate selected was sufficiently slow so that any variation in the soot ignition temperature $[24,25]$ could be observed. Each sample was analysed three times to assure the reproducibility. The TG-DSC and TG-DTG curves acquired revealed the differences in the soot oxidation behaviour between the fuels with and without the FPC treatments.

\section{Results and Discussion}

\subsection{Soot morphology, particle size and fractal dimension}

Figure 1 shows the low-magnification TEM images of soot samples from the combustion of diesel and biodiesel fuels, with and without the catalyst treatment. In general, the soot 
particles were found to be in the form of grape- or chain- like [26] agglomerates, which were composed of hundreds of spherical-shaped, basic soot units. These spherules were defined as “primary soot particles” and the large agglomerates were called "soot aggregates” [27]. Overall, there were no remarkable differences in terms of the morphologies, as revealed by the TEM images, between the soot collected from the untreated and FPC treated fuels.

High resolution TEM (HRTEM) images of the primary soot particles from the fuels tested are shown in Figure 2. It can be clearly seen that the soot samples all exhibited the classical coreshell structure, where long fringes were concentrically arranged along the edge and short fringes were randomly distributed in the core area. Examining the soot nanostructure, it was noted that there were no significant variations in the initial structures of the diesel and biodiesel soots due to the use of FPC. The lattice spacing was $4.02 \AA$ and $4.00 \AA$ for the RD and FPC-D (1:10000) soot, and 4.07 $\AA$ and $4.05 \AA$ for BD and FPC-B (1:10000) soot, respectively, suggesting that the carbon layers in the diesel/biodiesel soot remained unaffected by FPC during the early stage of the soot nucleation. It was also found that a slightly less ordered structure at nanoscale was captured in the outmost periphery of the RD soot, which consisted of disconnected carbon segments with shorter lengths. In contrast, the BD soot exhibited a highly ordered structure with onion-like radial carbon fringes, surrounded by a thin amorphous carbon layer (as marked in Figures 2c and 2d). The difference observed in the soot nanostructure between the RD and BD fuels was consistent with the literature [28-30] and may be attributed to more complete combustion of biodiesel in CI engines.

The sizes of the primary soot particles $\left(\overline{D_{p}}\right)$ were determined using the method reported elsewhere [18], which measures the particle diameter by imposing circular outlines over the spherical primary soot particles isolated on the TEM images. The results are shown in Figure 
3. Knowing $\overline{D_{p}}$, the average gyration diameter of the aggregates $\left(\overline{D_{g}}\right)$ and the fractal dimension $\left(D_{f}\right)$ are calculated using the power-law equation to reveal the aggregate size and the agglomeration mechanisms of soot. The details of the calculation procedure can be found in Ref. [17], and the results are summarised in Table 2.

From Figure 3 and Table 2, it is noted that the sizes of primary soot $\left(\overline{D_{p}}\right)$ and aggregates $\left(\overline{D_{g}}\right)$ from the diesel and biodiesel with FPC treatments were consistently smaller than those from the RD and BD fuels, respectively. This suggests that the fuel combustion was substantially enhanced by FPC, resulting in less soot precursors in the combustion zone and therefore the smaller primary soot and aggregates in sizes. Furthermore, the fractal dimensions $D_{f}$ of all soot samples were found to be at similar values of around 2. According to Meakin [31], $D_{f}$ above 1.8 implies that the soot particles are formed under a cluster-cluster growth mode. The similar $D_{f}$ values of soot from the diesel and biodiesel with and without the FPC treatments indicate that the mechanisms of the initial formation of the soot aggregates were unaffected by FPC.

It was also noted that the sizes of the primary soot and aggregates from BD were smaller than those from RD. This may be explained by the fact that BD is made of largely oxygenated hydrocarbons [7], which have inherently higher combustion reactivity, burn more completely and therefore, the smaller and less soot associated with biodiesel combustion.

\subsection{Soot oxidative property and kinetics}

Figure 4 illustrates the thermal behaviour of the soot samples from the combustion of the four fuels tested. Three major mass loss events accompanied with exothermic heat peaks (as marked on the plots) are clearly noticeable, corresponding to the evaporation and desorption 
of light hydrocarbons (light HCs) on the soot surfaces, the oxidation of heavy hydrocarbons (heavy HCs) attached to the soot and the dry soot oxidation [18]. The weight loss from each of these events was estimated from the TG-DSC curves (Figure 4a) and listed in Table 3 following the method in [25]. Figure 4a and Table 3 suggest that the distributions of major components in the soot from the two FPC treated fuels were not significantly changed in comparison to those from $\mathrm{RD}$ and $\mathrm{BD}$.

Moreover, two characteristic temperatures, namely the peak temperature $\left(T_{\text {peak }}\right)$ and burnout temperature $\left(T_{\text {burnout }}\right)$ for the dry soot oxidation were acquired from the TG-DTG curves (Figure 4b) following the method detailed in $[18,25]$ and compared in Table 4. $T_{\text {peak }}$ represents the temperature at which the maximum rate of mass loss due to soot oxidation occurs and a low $T_{\text {peak }}$ indicates easy ignition and vice versa. $T_{\text {burnout }}$ refers to the temperature at which the soot oxidation is completed. Note that the heating rate in the TGA experiments can affect these characteristic temperatures in that increasing the heating rate would shift $T_{\text {peak }}$ and $T_{\text {burnout }}$ to higher values. In the present study, $T_{\text {peak }}$ and $T_{\text {burnout }}$ were determined under a constant heating rate $\left(10^{\circ} \mathrm{C} \mathrm{min}^{-1}\right)$ to reveal and compare the differences among the soot samples from the four different fuels. It was found that the soot ignition temperature became lower, and $T_{\text {peak }}$ and $T_{\text {burnout }}$ for the given heating rate as listed in Table 4 were about $5^{\circ} \mathrm{C}$ lower than those of soot from the untreated fuels. This indicates that iron in FPC deposited on soot during combustion subsequently catalysed the oxidation of biodiesel soot, in the same way as it catalysed diesel soot oxidation in the combustion of FPC treated diesel [18].

Compared to those of the RD soot, the BD soot contained relatively higher volatile fractions with more light HCs and less heavy HCs, with the contents of dry soot and ash residues remained similar. The BD soot also ignited at a lower temperature and its $T_{\text {peak }}$ and $T_{\text {burnout }}$ 
shown in Table 4 were about $20^{\circ} \mathrm{C}$ lower than those of the RD soot. These suggest that the biodiesel soot is more reactive due primarily to their extra oxygen functionality, consistent with the literature reports $[22,28]$.

The kinetics of oxidation of the dry soot (from $520 \sim 660^{\circ} \mathrm{C}$ ) was further examined using the correlation between the kinetic rate equation and Arrhenius law, with the calculation procedures detailed elsewhere [18]. The kinetic parameters obtained are shown in Table 5, and the Arrhenius plots from the dry soot oxidation are displayed in Figure 5. Interestingly, the activation energy $E_{a}$ of soot from the FPC treated fuels was slightly higher than those from the corresponding $\mathrm{RD}$ and $\mathrm{BD}$, while the pre-exponential factor $A$ was $3 \sim 4$ orders of magnitude higher. It was also noted that the rate constant $k$ (where $k=A e^{-E_{a} / R T}$ ), independent of the gaseous reactant concentration, was consistently higher for the soot from the FPC treated fuels, confirming that the iron deposited on the soot catalysed the soot oxidation during the combustion of diesel and biodiesel. It should also be noted that $E_{a}$ of the BD soot was $195 \mathrm{kJmol}^{-1}$, significantly higher than that of the RD soot at $152 \mathrm{kJmol}^{-1}$, due to the highly ordered graphitic structure possessed by BD soot [32], while $A$ was three orders of magnitude higher at $1.2 \times 10^{9} \mathrm{~s}^{-1}$ in comparison with that of the RD soot at $2.2 \times 10^{6} \mathrm{~s}^{-1}$. Overall, as shown in Figure 5, $k$ for the BD soot was also higher, which again confirmed that the oxidative reactivity of the BD soot was higher than that of the RD soot.

\subsection{Mechanism of FPC in biodiesel soot formation processes}

Based on the aforementioned findings and those reported in our previous work, the mechanism of FPC affecting the biodiesel soot formation was proposed. Similar to the catalytic effect of FPC in diesel combustion, it was found in Ref [19] that the addition of FPC promotes biodiesel combustion by increasing the burning rate, flame temperature and 
shortening the burnout time, which leads to more complete combustion of gas-phase hydrocarbon fragments and less soot precursors to form the primary soot and aggregates, thus the smaller sizes of the primary soot and aggregates as observed in the present study. Then the FPC actively accelerates the oxidation of biodiesel soot formed, as indicated by the lower ignition temperature and higher oxidation rate. Following the aforementioned mechanism, the biodiesel combustion in a diesel engine is substantially improved by the FPC catalyst, resulting in reduced biodiesel fuel consumptions and lower overall soot emissions.

\section{Conclusions}

The effect of a ferrous picrate-based combustion catalyst on the nanostructure and oxidative properties of biodiesel soot from a CI engine has been systematically studied. The sizes of the primary soot and aggregates from FPC treated biodiesel were smaller than those of the BD soot, while the nanostructure and fractal dimension remained roughly the same, indicating that the formation mechanisms of the primary soot and aggregates remained unaffected by the catalyst. However, the oxidative reactivity of the biodiesel soot was increased by the FPC addition, with a lower ignition temperature and faster oxidation rate. Compared to the RD soot, the BD soot possessed a higher order in its nanostructure with smaller primary soot and aggregates in sizes. The oxidation of biodiesel soot also occurred at a lower temperature with a higher oxidation rate than that of diesel soot, indicating that the biodiesel soot has a higher reactivity.

The FPC catalyst was shown to promote biodiesel combustion in the CI engine, resulting in less soot precursors in the combustion zone and therefore the smaller primary soot and aggregates. In a later stage of the combustion process, FPC actively accelerates the soot 
oxidation as indicated by the lower ignition temperature and higher oxidation rate, leading to a significant reduction in the overall soot emissions from CI engines.

\section{Acknowledgement}

This research was supported by the Australian Research Council under the ARC Linkage Projects Scheme (Project Number: LP0989368) in partnership with Fuel Technology Pty Ltd and BHP Billiton Iron Ore Pty Ltd. 


\section{References}

1. W. Knecht, Energy 33 (2) (2008) 264-271.

2. T. V. Johnson, SAE Technical Paper No. 2006-01-0030, 2006.

3. M. A. Rady, A. S. Huzayyiln, A. H. Bawady, A. Dawood, Energ Convers Manage 45 (13-14) (2004) 2093-2112.

4. D. Li, Z. Huang, X. C. Lu, W. Zhang, J. Yang, Renew Energ 30 (6) (2005) 967-976.

5. A. K. Agarwal, K. Rajamanoharan, Appl Energ 86 (1) (2009) 106-112.

6. $\quad$ R. Behcet, Fuel Processing Technology 92 (6) (2011) 1187-1194.

7. M. S. Graboski, R. L. McCormick, Prog Energ Combust 24 (2) (1998) 125-164.

8. J. L. Xue, T. E. Grift, A. C. Hansen, Renew Sust Energ Rev 15 (2) (2011) 1098-1116.

9. M. Lapuerta, O. Armas, J. Rodriguez-Fernandez, Prog Energ Combust 34 (2) (2008) 198-223.

10. Y. Ma, M. Zhu, D. Zhang, in: The $4^{\text {th }}$ International Conference on Applied Energy, Suzhou (China), 2012.

11. A. Keskin, M. Guru, D. Altiparmak, Fuel 86 (7-8) (2007) 1139-1143.

12. M. Guru, A. Keskin, D. Altiparmak, Bioresource Technol 99 (14) (2008) 6434-6438.

13. G. R. Kannan, R. Karvembu, R. Anand, Appl Energ 88 (11) (2011) 3694-3703.

14. M. Guru, A. Koca, O. Can, C. Cinar, F. Sahin, Renew Energ 35 (3) (2010) 637-643.

15. M. Zhu, Y. Ma, D. Zhang, Applied Energy 91 (1) (2012) 166-172.

16. Y. Ma, M. Zhu, D. Zhang, Applied Energy 102 (0) (2013) 556-562.

17. Y. Ma, M. Zhu, D. Zhang, Applied Energy 113 (0) (2014) 751-757.

18. D. Zhang, Y. Ma, M. Zhu, Proceedings of the Combustion Institute 34 (1) (2013) 18691876.

19. M. Zhu, Y. Ma, D. Zhang, Proceedings of the Combustion Institute 34 (1) (2013) 15371544. 
20. D. G. Lee, A. Miller, K. H. Park, M. R. Zachariah, Int J Automot Techn 7 (6) (2006) 667-673.

21. J. H. Song, J. G. Wang, A. L. Boehman, Combust Flame 146 (1-2) (2006) 73-84.

22. J. H. Song, M. Alam, A. L. Boehman, U. Kim, Combust Flame 146 (4) (2006) 589-604.

23. G. Skillas, Z. Qian, U. Baltensperger, U. Matter, H. Burtscher, Combust Sci Technol 154 (2000) 259-273.

24. D. K. Zhang, T. F. Wall, A. G. Tate, Fuel 71 (11) (1992) 1247-1253.

25. S. Y. Yorulmaz, A. T. Atimtay, Fuel Processing Technology 90 (7-8) (2009) 939-946.

26. H. Wang, Proceedings of the Combustion Institute 33 (1) (2011) 41-67.

27. J. Xi, B. J. Zhong, Chemical Engineering \& Technology 29 (6) (2006) 665-673.

28. W. Merchan-Merchan, S. G. Sanmiguel, S. McCollam, Fuel 102 (2012) 525-535.

29. J. H. Song, M. Alam, A. L. Boehman, Combust Sci Technol 179 (9) (2007) 1991-2037.

30. K. Yehliu, R. L. Vander Wal, O. Armas, A. L. Boehman, Combust Flame 159 (12) (2012) 3597-3606.

31. P. Meakin, On Growth and Form, Martinus-Nijhoff, Boston, 1986.

32. B. Heinrich, F. Walter, Journal of Nuclear Materials 442 (1-3) (2013) 75-82. 


\section{Table Captions}

Table 1 Specifications of reference diesel (RD) and biodiesel (BD) fuels

Table 2 Comparison of the $\overline{D_{g}}$ and $D_{f}$ values of soot from the fuels tested

Table 3 Distribution (by weight percentage) of major components in soot from the fuels tested

Table 4 Peak temperature and burnout temperature of soot from the fuels tested

Table 5 Kinetic parameters of oxidation of soot from the fuels tested 
Table 1 Specifications of reference diesel (RD) and biodiesel (BD) fuels

\begin{tabular}{lccl}
\hline \multicolumn{1}{c}{ Parameters } & $R D$ & $B D$ & Analytical Method \\
\hline Viscosity $\left(\mathrm{cSt}\right.$ at $\left.40{ }^{\circ} \mathrm{C}\right)$ & 2.09 & 3.40 & ASTM D445 \\
Density $\left(\mathrm{kg} / \mathrm{m}^{3}\right.$ at $\left.15^{\circ} \mathrm{C}\right)$ & 838.5 & 883.5 & ASTM D1298 \\
Flash point $\left({ }^{\circ} \mathrm{C}\right)$ & 74 & 101 & ASTM D93 \\
Pour point $\left({ }^{\circ} \mathrm{C}\right)$ & -15 & -1 & ASTM D97 \\
Sulfur content $(\mathrm{ppm})$ & $<15$ & 0 & ASTM D1266 \\
Distillation range $\left({ }^{\circ} \mathrm{C}\right)$ & $177 \sim 360$ & $280 \sim 366$ & ASTM D86 \\
Calculated Cetane Index $(\mathrm{CCI})$ & 50.1 & 57.1 & ASTM D4737 \\
\hline
\end{tabular}


Table 2 Comparison of the $\overline{D_{g}}$ and $D_{f}$ values of soot from the fuels tested

\begin{tabular}{lcc}
\hline & $\overline{D_{g}}(\mathrm{~nm})$ & $D_{f}$ \\
\hline RD soot & $295 \pm 6$ & $2.07 \pm 0.06$ \\
FPC-D (1:10000) soot & $283 \pm 5$ & $2.04 \pm 0.06$ \\
BD soot & $202 \pm 4$ & $2.00 \pm 0.05$ \\
FPC-B (1:10000) soot & $186 \pm 4$ & $1.95 \pm 0.05$ \\
\hline
\end{tabular}

Note: $\overline{D_{g}}$ is the average gyration diameter, representing the average diameter of the aggregates;

$D_{f}$ is the fractal dimension, indicating the mechanisms of soot agglomeration and growth. 
Table 3 Distribution (by weight percentage) of major components in soot from the fuels tested

\begin{tabular}{lcccc}
\hline & $\begin{array}{c}\text { Light HCs } \\
\left(25 \sim 300^{\circ} \mathrm{C}\right)\end{array}$ & $\begin{array}{c}\text { Heavy HCs } \\
\left(300 \sim 520^{\circ} \mathrm{C}\right)\end{array}$ & $\begin{array}{c}\text { Dry soot } \\
\left(520 \sim 660^{\circ} \mathrm{C}\right)\end{array}$ & $\begin{array}{c}\text { Ash residue } \\
\left(660^{\circ} \mathrm{C} \sim 700^{\circ} \mathrm{C}\right)\end{array}$ \\
\hline RD soot & 44 & 22 & 28 & 6 \\
FPC-D (1:10000) soot & 42 & 20 & 32 & 6 \\
BD soot & 54 & 16 & 27 & 3 \\
FPC-B (1:10000) soot & 51 & 16 & 30 & 3 \\
\hline
\end{tabular}


Table 4 Peak temperature and burnout temperature of soot from the fuels tested

\begin{tabular}{lcc}
\hline & $T_{\text {peak }}\left({ }^{\circ} \mathrm{C}\right)$ & $T_{\text {burnout }}\left({ }^{\circ} \mathrm{C}\right)$ \\
\hline RD soot & 628 & 655 \\
FPC-D (1:10000) soot & 622 & 650 \\
BD soot & 610 & 632 \\
FPC-B (1:10000) soot & 596 & 626 \\
\hline
\end{tabular}

Note: $\quad T_{\text {peak }}$ - peak temperature from DTG curve of soot oxidation;

$T_{\text {burnout }}$ - burnout temperature from DTG curve of soot oxidation. 
Table 5 Kinetic parameters of oxidation of soot from the fuels tested

\begin{tabular}{lcl}
\hline & $E_{a}\left(\mathrm{~kJ} \mathrm{~mol}^{-1}\right)$ & \multicolumn{1}{c}{$A\left(\mathrm{~s}^{-1}\right)$} \\
\hline RD soot & $152 \pm 2$ & $2.2 \times 10^{6}$ \\
FPC-D (1:10000) soot & $209 \pm 4$ & $1.3 \times 10^{10}$ \\
BD soot & $195 \pm 3$ & $1.2 \times 10^{9}$ \\
FPC-B (1:10000) soot & $240 \pm 5$ & $2.2 \times 10^{12}$ \\
\hline
\end{tabular}




\section{Figure Captions}

Figure 1 Low-magnification TEM images of soot from (a) RD; (b) FPC-D (1:10000); (c) BD and (d) FPC-B (1:10000) with the engine operating at 2800rpm speed and $5.5 \mathrm{Nm}$ load

Figure 2 HRTEM images of soot from (a) RD; (b) FPC-D (1:10000); (c) BD and (d) FPC-B (1:10000) with the engine operating at 2800rpm speed and 5.5Nm load

Figure 3 Size distributions of primary soot particles from the fuels tested with the engine operating at 2800rpm speed and 5.5Nm load

Figure 4 Comparison of (a) TG-DSC and (b) TG-DTG curves (in air atmosphere) of soot from the fuels tested with the engine operating at 2800rpm speed and 5.5Nm load

Figure 5 Arrhenius plots for the oxidation of soot from the fuels tested 
Figure 1
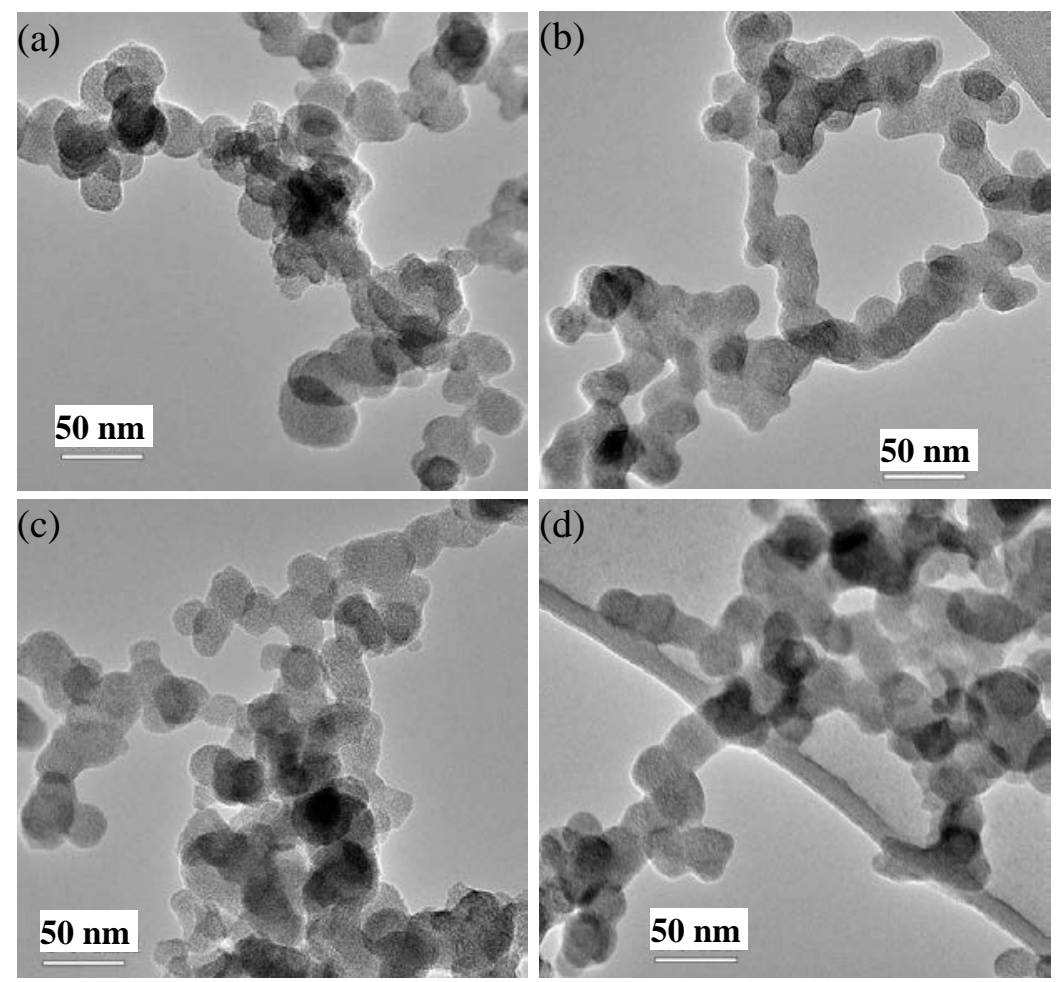

Figure 1 Low magnification TEM images of soot from (a) RD; (b) FPC-D (1:10000); (c) BD and (d) FPC-B (1:10000) with the engine operating at 2800rpm speed and $5.5 \mathrm{Nm}$ load 
Figure 2
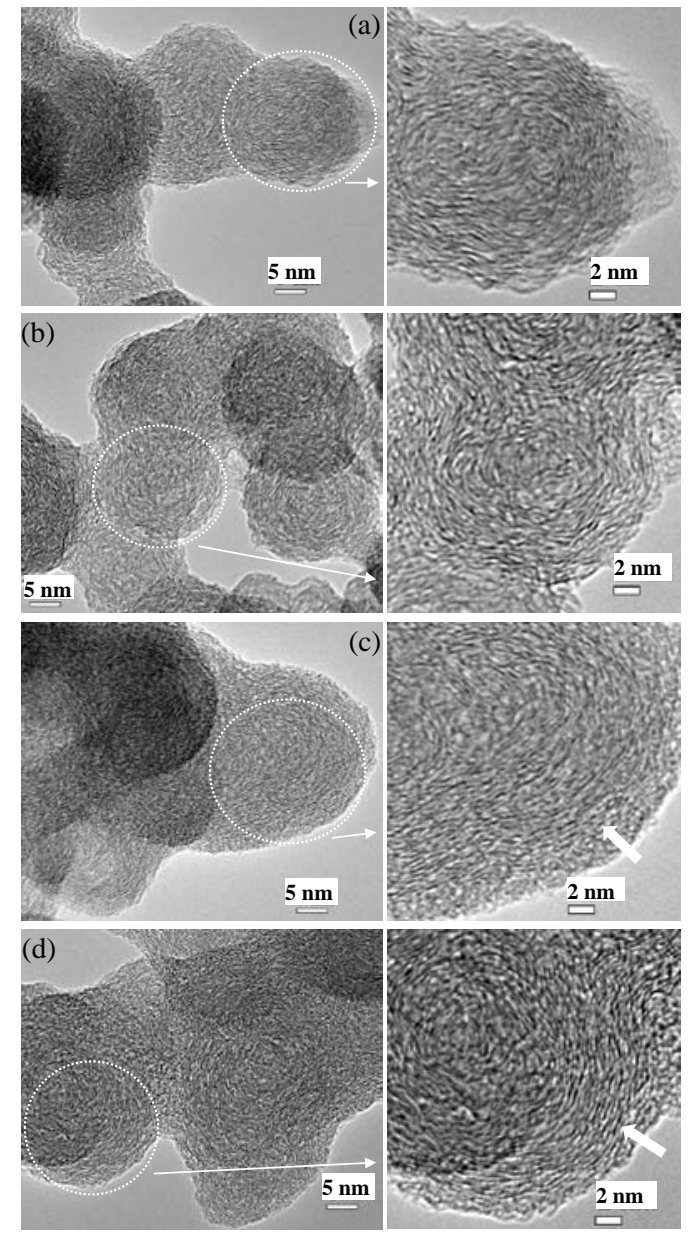

Figure 2 HRTEM images of soot from (a) RD; (b) FPC-D (1:10000); (c) BD and (d) FPCB (1:10000) with the engine operating at 2800rpm speed and 5.5Nm load 
Figure 3
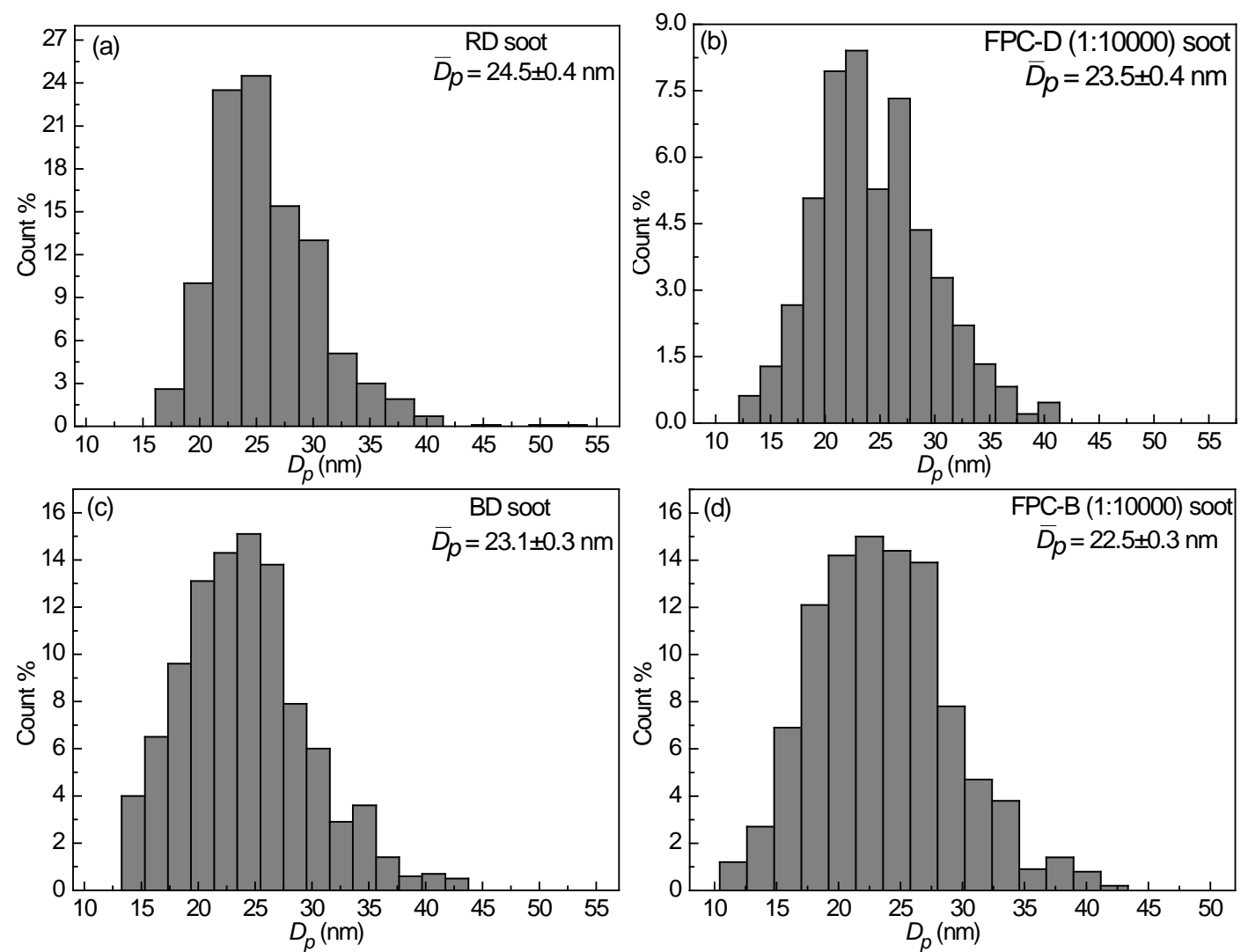

Figure 3 Size distributions of primary soot particles from the fuels tested with the engine operating at 2800rpm speed and 5.5Nm load 
Figure 4
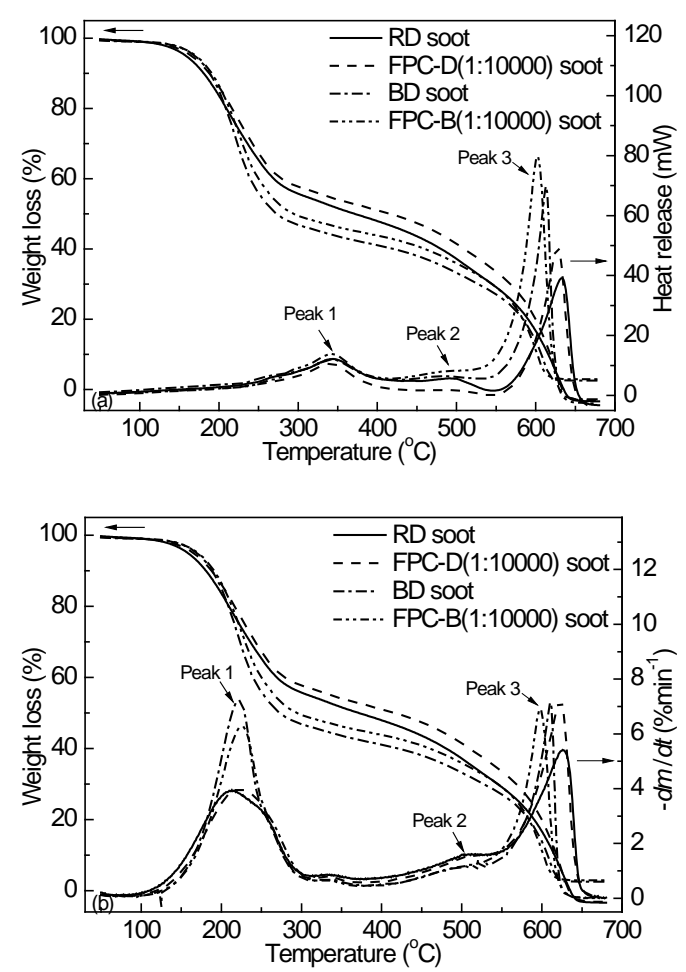

Figure 4 Comparison of (a) TG-DSC and (b) TG-DTG curves (in air atmosphere) of soot from the fuels tested with the engine operating at 2800rpm speed and 5.5Nm load 
Figure 5

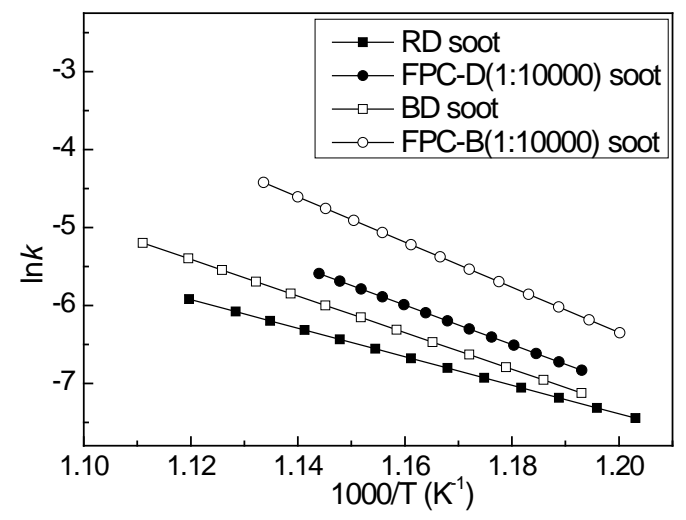

Figure 5 Arrhenius plots for the oxidation of soot from the fuels tested 